\title{
A CONCEPÇÃO DE EDUCAÇÃO PARA CIDADANIA NA EDUCAÇÃO DE JOVENS E ADULTOS: Aspectos teóricos e práticos
}

\author{
Ana Helena Lima de Souza \\ Maria Sacramento Aquino \\ Antonio Amorim ${ }^{(*)}$
}

\section{INTRODUÇÃO}

Através da legislação, do posicionamento de organismos nacionais e internacionais que tratam da formação para a cidadania persiste a viabilidade da concepção educativa que legitima a escola como sendo a responsável pela formação cidadã, como preparadora do sujeito para viver em sociedade. Embora, essa discussão caiba para todos os segmentos da educação, é sobre a formação para cidadania, posta para a educação de jovens e adultos, que questionamos alguns documentos legais, que tratam da questão em si, quanto às práticas e as crenças da própria escola no trabalho com a EJA.

A reflexão deste artigo tem como foco a abordagem em torno da formação cidadã que vem sendo proposta para a Educação de Jovens e Adultos (EJA), segmento da educação básica, provocando confrontos e indagações, na percepção de que a situação cotidiana da escola requer, de fato, um estudo aprofundado para melhor definição de uma concepção de cidadania, que faça sentido para a demanda de estudantes da EJA.

Nessa perspectiva, urgem diagnósticos que contemplem a forma como a escola reconhece a participação desses estudantes, oriundos de diferentes contextos: social, cultura, econômico e político, assim como a compreensão que eles apresentam sobre seus direitos de cidadão. De acordo Arroyo (2010, p. 72) a pedagogia das escolas não avança na reflexão sobre o social e persiste a valorização de uma

\footnotetext{
${ }^{(*)}$ Ana Helena L. Souza. Mestre pelo Programa de Mestrado Profissional de Educação de Jovens e Adultos (MPEJA) da Universidade do Estado da Bahia (UFBA). Diretora de Escola Pública em Feira de Santana (BA). E-mail: anahelenalima@hotmail.com.

Maria S. Aquino. Professora titular do Programa de Mestrado Profissional de Educação de Jovens e Adultos (MPEJA) da UFBA. Doutorado em Educação pela Universidade do Rio Grande do Norte (UFRN). E-mail: aquinomaria@yahoo.com.br.
}

Antonio Amorim. Professor pleno do Programa de Mestrado Profissional de Educação de Jovens e Adultos (MPEJA) da UFBA. Doutorado em Psicologia pela Universidade de Barcelona (Espanha). E-mail: antonioamorim52@gmail.com. 
[...] visão negativa do convívio social, a pedagogia não tem condição de refletir sobre as transformações políticas que vem acontecendo na sociedade moderna e tende a se fechar em saídas individuais e morais, como transformação interna do homem pela educação.

Nessa definição, a escola não pode pensar e trabalhar uma determinada concepção de cidadania, com toda sua incongruência, sem refletir sobre seu projeto político e pedagógico de formação para a cidadania. Assim como, entendemos que ela não pode perder de vista o reconhecimento de que os jovens e adultos, já concebem uma cidadania, ainda que não tenham consciência crítica sobre ela. Cabe a escola criar possibilidades a esses sujeitos de direitos, o exercício de resistência e de luta para o enfrentamento das condições sociais postas no seu cotidiano.

Propomos que esse exercício reflexivo, indagador e imprescindível, embora nada fácil, seja colocado como meta pelas escolas e por seus educadores, em respeito aos estudantes e aos próprios educadores que formam o coletivo da educação de jovens e adultos, no Brasil. Para tanto, questionamos: a escola se propõe a trabalhar uma formação para estudantes jovens e adultos como sujeitos críticos e políticos? E, ainda trabalha a concepção de cidadania no contexto da diversidade de realidades sociais vivenciadas pelos estudantes em suas comunidades?

Falar da essência do que significa cidadania, justamente, para um coletivo da população que teve um dos seus direitos civis e a educação, negados, no tempo histórico, é como desconsiderar as suas experiências sociais, esquecendo que se trata de um jovem estudante e trabalhador. Isso representa, sem dúvida, uma maneira de, mais uma vez, de desrespeitá-los, de negar o direito à escola (GADOTTI, 2014).

A proposição de compreender a formação na EJA, como sendo uma preparação para cidadania, como algo específico da escola, como sendo uma missão de preparar para a vida, geralmente, ignora a trajetória de vida dos estudantes, da histórica negação das reais necessidades deste segmento importante da sociedade. De um modo geral podemos afirmar que isso gera uma perspectiva de cidadania para conformação, com a adoção de políticas públicas que servem mais para esconder a verdadeira realidade educacional, em que vivem os estudantes da EJA. É nesse sentido que as propostas políticas e pedagógicas para educação de jovens e adultos devem ser pensadas, para a superação de uma pedagogia do conformismo, da não aceitação do modelo de sociedade que resiste em reconhecer que os sujeitos sociais são capazes de pensar a própria sociedade.

Para analisar esta situação organizamos este artigo a abordagem qualitativa de investigação, sendo instrumentalizada pela técnica da pesquisa bibliográfica, que, segundo Boccato (2006) busca 
a resolução de um problema e considera os referenciais teóricos publicados, analisando e discutindo as várias contribuições científicas existentes sobre a temática. Deste modo, para assegurar esse diálogo reflexivo recorremos ao pensamento e práticas propostos por Freire (1991), Arroyo (2012 e 2013), Frigotto (2012) e Tonet (2013). Eles convergem na defesa do sentido reflexivo que deve existir no repensar a cidadania e a formação na educação de jovens e adultos. Eles defendem a necessidade de que sejam repensadas as práticas políticas e pedagógicas da educação de jovens e adultos, reconhecendo que este segmento social se forma, também, em outros espaços, e que aprendem a cidadania de diferentes modos, inclusive, pela negativa dos seus direitos sociais.

\section{A EXPERIÊNCIA SOCIAL E O PAPEL EDUCADOR NA ESCOLA: A VALORIZAÇÃO DA FORMAÇÃO PARA A CIDADANIA}

A inserção do direito a uma educação que reconheça as experiências sociais dos seus estudantes para a concepção de formação para a cidadania tem sido refletida por diversos teóricos, nesse entendimento, é preciso reconhecer que "[...] a espécie humana é construída por ela mesma no decorrer da história: o homem é construído enquanto espécie humana. Também ele é construído como membro de uma sociedade e de uma cultura [...]" (CHARLOT, 2013, p. 166). Logo, percebemos a necessidade da escola reconhecer essa constituição e de forma política, garantir a formação para questionar a sociedade, as formas de dominação presentes nos modelos educativos de nossas instituições de ensino, sobretudo, da visão de mundo que se tem sobre os sujeitos da educação de jovens e adultos.

Urge práticas educativas na perspectiva de romper com o pensamento dominante que atribui ao coletivo popular uma natureza inferior, de anticidadão, de anti-humano, de forma a reconhecêlos como sujeitos inferiores. Há que se romper com as “[...] imagens dos coletivos como marginais terminam sendo funcionais a realimentar políticas e pedagogias e o próprio pensamento socioeducativo que se autolegitimam em oferecer pontes, percursos de passagem" (ARROYO, 2012, p. 41).

Vale ressaltar que sobre a EJA reside a visão de oportunidade dada, ignorando o princípio do direito a educação, educação está subtraída de um povo colocado à margem por não poder usufruir dos seus direitos, que vêm sendo historicamente negados. Essa superação não pode ocorrer na EJA sem que seja garantido o espaço de reflexão em torno da história de enfrentamento da opressão, do reconhecimento das políticas já existentes com base nos movimentos de cultura popular, e a constante luta em busca do respeito à diversidade dos sujeitos na sociedade. 
Tão intenso quanto estudar a EJA é chegar à compreensão de que muitas soluções para assegurar uma educação de jovens e adultos de qualidade, no que se refere à importância dessa educação para os sujeitos sociais, esbarram-se no olhar preconceituoso daqueles que não reconhecem a trajetória de vidas de muitos brasileiros que ficam de fora da divisão dos bens, direitos civis, que podem assegurar maior dignidade humana, conforme define a Lei maior, Constituição Federal, com a atribuição do Estado Democrático de Direito.

Art. 1ํ. A República Federativa do Brasil, formada pela união indissolúvel dos Estados e Municípios e do Distrito Federal, constitui-se em Estado Democrático de Direito e tem como fundamentos: I. a soberania; II. a cidadania; III. a dignidade da pessoa humana; IV. os valores sociais do trabalho e da livre iniciativa; V. o pluralismo político. (BRASIL, 1988, p.14).

Portanto, de qual cidadania podemos falar numa proposta de educativa que não respeita a educação como direito subjetivo a todos, uma vez que os seus mecanismos concorrem justamente para a permanência de um cenário educacional em que os jovens e adultos não são respeitados.

E assim, na relação educação e cidadania faz necessário reconhecer que o direito e o acesso ao processo educativo tornam-se o constituinte das possibilidades de tomada da própria consciência de uma cidadania, faz-se necessário repensar qual o lugar da qualidade do trabalho, em respeito as trajetória dos estudantes trabalhadores.

Parece difícil pensar um trabalho educativo que efetivamente se articule aos interesses dos trabalhadores, das classes populares, sem ter como ponto de partida e de chegada o conhecimento, a consciência gestada no mundo do trabalho, da cultura, das múltiplas formas como estes trabalhadores produzem sua existência (FRIGOTTO, 2012.p.28).

O conhecimento dos estudantes jovens e adultos é aquele de maior valorização para eles próprios, que se amplia e se transforma à medida que sua realidade é pensada e confrontada. Daí, a importância de lutarmos por uma educação libertadora, para que esse mesmo ponto de partida, o conhecimento, não seja desvirtuado e usado para ampliação do pensamento dominante, de aceitação de uma cidadania posto no binômio: direitos e deveres, no qual os deveres sobrepõem e barganham o direito de pensar, criticamente, dos estudantes.

Para Paiva (2011) é preciso desconfiar da promoção da educação de jovens e adultos, sobretudo, da pretensão que existe por trás do discurso da inclusão, que trás a perspectiva da oferta de escolarização, como sendo um suposto papel integrador do estado, de modo a considerar os estudantes jovens e adultos como excluídos.

Certamente, a discussão sobre inclusão na EJA somente se adéqua às vozes ressoantes de um ideal de sociedade forjada por uma cidadania inquestionável, sobre o ideal de direitos e deveres. 
Ignorar os processos históricos de preconização do coletivo popular é fortalecer o paradigma de uma sociedade de conformidade, que anula o papel crítico da escola, quando esta deveria se propuser a refletir o seu papel social e cultural, deixando de reproduzir um modelo de sociedade dominante que existe hoje. Para Arroyo (2012, p.80):

[...] quando se ignora a precarização do viver dos educadores e educandos se cai a exigência descabidas ou se responsabiliza uns e outros por fracassos em avaliações de resultados. As vítimas desse preconizado sobreviver, ainda, são vitimadas nos processos escolares e responsabilizados pelo emprego e pela pobreza.

Para Arroyo é pretensioso o paradigma de formação para a cidadania para sujeitos que encontram nos modos de vida preconizados, as grandes lições de uma cidadania que está posta no campo dos direitos como legítimos, essencialmente, no papel, mas não se institui de forma prática e ativa. Conceber uma cidadania plausível e concreta, que não negue as experiências de vidas dos seus sujeitos, despretensiosa de ideologia de estado, certamente, nesse modelo de educação, que se sustenta na perspectiva de inclusão, não atenderá de fato a perspectiva de uma formação para cidadania critica e emancipadora.

Monteiro (2011, p. 16) trás a ideia de formação comprometida com a cidadania, num sentido de favorecimento para uma formação que não se dá primeira e unicamente na escola, mas que ela pode favorecer a reflexão sobre a mesma, uma vez que: "[...] um trabalho de formação imbricado na cidadania deve priorizar as mudanças de valores, de atitudes, de posições, de comportamentos e de crenças em favor da prática da tolerância, da paz, e do respeito ao ser humano." Trata-se de uma formação, que segundo a autora, não pode desassociar da discussão sobre democracia e direitos humanos, “[...] tendo como foco a democracia e os direitos humanos, que a formação cidadã encontra espaço para ampliar sua atuação e o exercício da cidadania” (p. 16).

Uma tarefa desafiadora para a EJA é reconhecer a importância de considerar que a cidadania como constitutivo do sujeito social, a que requer ser concebida dentro de um processo de construção e ressignificação do ser cidadão, não como algo definitivo, mas para uma cidadania ativa.

Mas a educação está presente também na luta cotidiana dos cidadãos por direitos individuais e coletivos. E é nesta luta que se apreende o compromisso com o respeito pelos direitos de outras pessoas ou grupos sociais, portanto, com seus deveres. Este movimento da sociedade chamamos de "cidadania ativa", que se distingue da cidadania passiva, aquela outorgada pelo Estado, com a ideia moral da tutela e do favor. (HADDAD, 2003, p 25).

Sendo assim, a EJA não pode trabalhar na conformação de uma cidadania sem reconhecer o processo de luta que resulte em transformações individuais e coletivas. Devemos lembrar que os 
passos importantes para conquistas de novos direitos, e para maior abertura democrática foram dados na luta para a construção de uma cidadania plena. Entretanto, no momento histórico e político em que vivemos, esta luta pela cidadania encontra-se sob a ameaça de retrocesso, a partir das diretrizes políticas postas em prática, que reproduz, a nosso ver, a dura cerviz de uma sociedade de direitos restritos e elitizados, que não suporta ver a horizontalidade de direitos e do reconhecimento de todas as pessoas de forma igual.

É preciso reconhecer que as políticas de EJA, até então conquistadas, resultaram de lutas, sobretudo de movimento sociais, e que, certamente, esse movimento antidemocrático, que demarcam as políticas brasileiras, nesse final de década, exigirá maior engajamento social, em defesa de políticas de direito para uma educação libertadora.

\section{A PROPOSTA LEGISLATIVA PARA FORMAÇÃO CIDADÃ NA EDUCAÇÃO DE JOVENS E ADULTOS}

A Lei de Diretrizes e Bases 5.692/96, no seu art. 2, afirma que a educação tem por excelência o desenvolvimento pleno para o preparo do exercício da cidadania e da qualificação para o trabalho. Mas, de que desenvolvimento pleno e de qual cidadania mesmo a lei está falando? Qual cidadania será esta, se é possível ela ser constituída, ser formada no modelo de sociedade que temos, senão, a partir do seu confronto com o contexto em que se insere?

A sensação de esvaziamento de palavras para responder a tais questões, possivelmente, ocorre pelo próprio vazio de uma cidadania fortemente almejada, garantida na legislação e ao mesmo tempo negada aos coletivos de estudantes jovens e adultos, assim como aos seus educadores.

Portanto, as evidências apontam que defender e definir um conceito para cidadania, nesse contexto, não é essencialmente o mais importante nesta reflexão. O contexto sinaliza que o imprescindível, aqui, é pensar e defender uma formação para cidadania que parta, justamente, do reconhecimento e da luta pelo direito à cidadania, uma luta visceralmente acirrada, que busque nas marcas e trajetórias de vidas dos sujeitos, conhecimentos que componham os projetos políticos pedagógicos para o coletivo da EJA.

Essa urgente necessidade de garantir uma formação para a cidadania, que reconheça os seus sujeitos e respeite as suas especificidades, vem a ser uma exigência na EJA, de forma, a reconhecer que a luta pelos direitos sociais na sociedade não é individualizada, não é de um só sujeito, mas de um coletivo que se forma na diversidade de outros coletivos. De acordo Arroyo (2012, p.24), 
Reconhecer os jovens e adultos como membros de coletivos traria um outro horizonte para a EJA. Superar a ideia de que trabalhamos com percursos individuais, para tentar mapear que coletivos a frequentam. O coletivo negro, o coletivo mais pobre, o coletivo de trabalhadores, o coletivo dos sem-trabalho, coletivo das mulheres.

Observamos que se trata de um coletivo formado de muitos outros coletivos, que, em comum, tem a negação histórica de direitos civis, assim como, a luta por esses direitos. De acordo com Arroyo (2014), a EJA não pode negar a sua essência formativa, oriunda dos diferentes movimentos sociais populares, sobretudo, dos movimentos do operário do campo e da cidade, da história da relação entre direito ao trabalho e de direito a cidadania, que "[...] diante dessa riquíssima história podemos dizer que os direitos cidadãos foram aprendidos no avanço dos direitos do trabalho. A consciência de ser trabalhador foi levando ao avanço da consciência da cidadania" (ARROYO, 2014, p. 14).

O direito a cidadania deve ser a primeira promulgação de um paradigma de educação para a emancipação, constatando-se que a luta pelo direito negado já faz parte de uma formação, sendo que, primeiramente, ocorre fora da escola, cabendo à mesma reconhecer essas experiências de forma a interrogá-las, em seu processo de reelaboração do conhecimento. A histórica luta por uma educação crítica, mais progressista, com o ideal de uma formação cidadã, exige processo de conscientização, do pensar crítico sobre a realidade. Não esquecendo que em Freire a conscientização resulta de um processo que rompe com a visão ingênua do homem, em relação ao trabalho, para a construção de sua libertação da condição de oprimido, de forma a alcançar melhor consciência crítica, para o exercício da criticidade.

A criticidade para nós implica na apropriação crescente pelo homem de sua posição no contexto. Implica na inserção, na sua integração, na representação objetiva da realidade. Daí a conscientização ser o desenvolvimento da tomada de consciência. Não será por isso mesmo apenas resultante das modificações econômicas, por grandes e importantes que sejam. A criticidade, como entendemos, há de resultar de trabalhos pedagógicos crítico, apoiado em condições históricas propícias. (FREIRE, 1991, p. 69).

A educação de jovens e adultos, ao assumir o papel de trabalhar a cidadania, não pode começar, senão, do reconhecimento de que os seus sujeitos precisam exercitar a criticidade, da tomada de uma conscientização crítica de sua realidade. Por isso mesmo, entendemos que a EJA não pode distanciar-se dos princípios fundamentais da Educação Popular, que emerge, sobretudo, pela luta, pela liberdade do pensar e do questionar o mundo, de uma pedagogia para a libertação, fortemente apregoada por Freire. 
Fora dessa perspectiva, a escola vai continuar com a visão de desigualdade entre sociedade e cidadania, de equilíbrios entre direitos e deveres, uma desigualdade dos coletivos populares, sobretudo, das pessoas jovens e adultas, que ficam fora deste processo. A história registra que num modelo de sociedade que predomina a exploração do homem pelo homem, alienando-o no próprio mundo do trabalho, dificilmente, se consegue estabelecer igualdade de acesso aos direitos para todos, logo, não há igualdade.

A educação de jovens e adultos, na busca por uma educação para a liberdade, deve romper com o modelo de educação que visa à formação, unicamente, para o mundo do trabalho. A concepção de educação para a liberdade se preocupa, primeiramente, com o humano, que se forma no social e no relacional; com o humano que se emancipa quando se liberta daquilo que o oprime. Neste caso, a opressão advém, de fato, da relação com o trabalho, o qual demarca o nosso modelo de sociedade. Não seriam necessárias muitas palavras para o convencimento de que vivemos numa sociedade de classe, bastando perguntar qual lugar ocupa, na sociedade, muitos dos nossos estudantes que compõem o coletivo da EJA e da escola pública como um todo.

Como pensar uma concepção de educação para emancipação dos jovens e adultos, homens e mulheres, num contexto de sociedade que visa uma educabilidade unicamente para o mundo do trabalho? Na prática tem sido possível? Para Tonet (2012), educar de forma a promover emancipação só pode se dá no tempo livre que o homem tem para pensar e se organizar livremente, o que dificilmente acontece numa sociedade que aliena o homem ao mundo do trabalho.

Embora Ivo Tonet (2012) reafirme não ser possível uma educação emancipadora, nesse modelo social, por alienação ao mundo do trabalho, o autor reconhece que podem existir atividades educativas emancipadoras, que contribuam com a perspectiva da formação política. Paulo Freire, no curso de seu pensamento epistemológico de educação, orienta que a emancipação não pode ocorrer de fato enquanto houver opressão. Para tanto, se faz necessário reconhecer a importância primeira de uma educação para liberdade, nos levando a acreditar que a primeira condição para a libertação e a desalienação, sendo necessário proceder na reflexão e na visão do homem sobre sua condição social e política.

Liberdade esta que ao tirar o sujeito da condição de oprimido, dono de uma consciência ingênua da realidade, miraculosa e fantástica, o permite pensar de forma crítica, partindo para uma consciência mais real, logo, libertária, vindo dessa educação libertária a possibilidade de sua emancipação. É dessa educação que os currículos comumente postos para a educação de jovens e 
adultos se distanciam, e se sobrepõem aos conhecimentos postos como sendo necessários, para a consolidação de um processo formativo que reconhece e valoriza o ser humano.

\section{CONSIDERAÇÕES FINAIS}

Nesta reflexão, em torno da discussão sobre formação para cidadania, na educação de jovens e adultos, as evidências apontam que, de fato, não faz sentido essa discussão se não houver a predisposição de indagar a diversidade de realidades sociais, que são vivenciadas por seus estudantes. É desconsiderar que o conhecimento da escola a ser valorizado deve ser o conhecimento social, o reconhecimento dos direitos sociais que visa ao fortalecimento de uma cidadania para dignidade da pessoa humana.

Percebemos também que, refletir a formação para cidadania incide, de fato, na busca por um modus operandi que faça sentido, que dialogue com a realidade vivida pelos estudantes da EJA, para a superação de uma formação para cidadania que leva à conformidade.

Que discutir formação cidadã sem articular a discussão sobre os direitos que deveriam ser de fato legítimos, num estado democrático de direitos, é sem dúvida incoerente e inócua para o processo de conscientização que a escola deve favorecer aos seus estudantes. Somente a partir da reflexão sobre as suas realidades, dos direitos negados, facilmente identificados nas relações e experiências sociais vividas, os estudantes podem encontrar na escola o espaço para refletirem suas realidades, reconstruírem seus pensamentos e olhares sobre a sociedade em que vivem.

Aprendemos que os jovens e adultos, por viverem em sociedade, constroem seus conceitos e buscam se estabelecer nas condições da comunidade em que estão inseridos. Que a escola deve favorecer a reflexão sobre a participação destes estudantes, para atuar na superação de muitas das suas visões de conformismo e de alienação a um modelo de sociedade, que tem modos de vidas muitas vezes caracterizados por condições precárias de vida e pela negação dos direitos civis.

Sugerimos que o Projeto Político Pedagógico busque estratégias de orientação aos estudantes, no sentido de ajudá-los a realizar a sua vocação ontológica, a sua inserção na construção da sociedade que atua na direção de mudanças no processo de precarização do contexto social, e, assim exercitar a substituição, geralmente mágica da realidade por uma reflexão mais crítica e libertadora.

No momento em que, os estudantes da EJA sejam reconhecidos como sendo sujeitos sociais, homens, mulheres, trabalhadores e trabalhadoras, com suas trajetórias de vidas, a concepção de uma cidadania permitirão que esses sujeitos dialoguem com os saberes, com suas realidades, de forma 
reflexiva e crítica, num movimento de emancipação que promova a indagação sobre suas experiências, os seus processos políticos e sociais.

Assim, destacamos ser urgente a construção de um processo educativo nas classes da EJA, que exercite no seu interior, as experiências para a formação crítica e conscientizadora, de forma que venha a favorecer a criatividade da educação problematizadora. Desta forma, concluímos que a concepção de cidadania pode ser estabelecida com a prática, num movimento de transformações dos sujeitos sobre suas realidades.

\section{REFERÊNCIAS}

ARROYO, Miguel G. Currículo, território em disputa. 5. Petrópolis, RJ: Vozes, 2013.

Outros sujeitos, outras pedagogias. Petrópolis, RJ: Vozes, 2012.

. Educação de jovens-adultos: um campo de direitos e de responsabilidade pública. In: SOARES, Leôncio; GIOVANETTI, Maria Amélia G. C.; GOMES, Nilma Lino. (Orgs.). Diálogos na educação de jovens e adultos. Belo Horizonte: Autêntica, 2005.

BRASIL. Constituição (1988). Constituição da República Federativa do Brasil. Diário Oficial da União. Brasília: Congresso Nacional, 05 out. 1988. Anexo.

BRASIL. Lei 9.394, de 20 de dezembro de 1996. Estabelece as diretrizes e bases da educação nacional. Diário Oficial da União. Brasília: Poder Legislativo, 23 dez. 1996, sec. I, n. 248, p. 27.833.

CHARLOT, Bernard. A mistificação pedagógica: realidades sociais e processos ideológicos na teoria da educação. São Paulo: Cortez, 2013.

FREIRE, Paulo. Pedagogia do oprimido. Rio de Janeiro: Paz e Terra, 1987.

A educação na cidade. São Paulo: Cortez, 1991.

. Conscientização: teoria e prática da libertação: uma introdução ao pensamento de Paulo Freire/Paulo Freire; 1921[tradução de Kátia de Mello e Silva; revisão técnica de Benedito Eliseu Leite Cintra]. São Paulo: Cortez \& Moraes, 1979.

1996.

. Pedagogia da autonomia: saberes necessários à prática educativa. (Coleção Leitura). São Paulo: Paz e Terra,

Educação como prática da liberdade. Rio Janeiro, Paz e Terra, 1997.

GADOTTI, Moacir. Por uma política nacional de educação popular de jovens e adultos. São Paulo: Moderna/Fundação Santillana, 2014.

. Um cenário possível da educação de jovens e adultos no Brasil. In: ANTUNES, A. M. B. R. Alfabetização de jovens e adultos: manual do alfabetizador. Rio de Janeiro: Escola Multimeios, 2009.

. A gestão democrática na escola para jovens e adultos: idéias para tornar a escola pública uma escola de EJA. Texto preparado para o I Encontro de Reflexão sobre a Reestruturação e Reorientação Curricular da Educação de Jovens e Adultos - "Uma nova EJA para São Paulo" - realizado pela Secretaria Municipal de Educação de São Paulo, dia 14 de março de 2003.

HADDAD, Sérgio. Education for younth and adults, for the promotion of an active citizenship, and for the development of a culture and aconscience of peace and human rights. Agenda for the future six years later - ICAE Report. International Council for Adults Education - ICAE. Montevideo. 2003.

TONET, Ivo. Educação contra o capital. São Paulo: Instituto Lukács, 2012. 


\section{THE CONCEPT OF EDUCATION FOR CITIZENSHIP IN ADULT AND YOUTH} EDUCATION: THEORETICAL AND PRACTICAL ASPECTS

\section{RESUMO}

Este artigo apresenta a abordagem em torno da importância de que seja identificada uma concepção de cidadania, mais específica, para a Educação de Jovens e Adultos (EJA), reconhecendo o modo de vida dos estudantes, as experiências sociais, assim como, refletir a questão do desrespeito histórico aos direitos civis dos jovens e adultos. A formação para a cidadania é analisada através de documentos oficiais e posicionamentos de teóricos, a exemplo da defesa de Arroyo, de Freire e outros. Nas conclusões destacamos que a formação para cidadania tenha inspirações na interrogação da realidade social dos educandos, do processo reflexivo acerca da superação da consciência ingênua existente.

Palavras-chaves: Educação de Jovens e Adultos; Cidadania; Consciência ingênua e crítica.

\section{ABSTRACT}

This article presents the approach around the importance of which is identified a conception of citizenship, more specifically, for youth and adult education (EJA), recognizing the students ' way of life, social experiences, as well as reflect the issue of disrespect to civil rights history of young people and adults. Training for citizenship is examined through official documents and positions of theorists, such as the defense of Arroyo, Freire and others. The conclusions highlight that training for citizenship have inspirations in the interrogation of the social reality of learners, reflective process about the overcoming of naive consciousness.

Keywords: adult and youth education; Citizenship; Naive and critical awareness.

Submetido jun. 2016

Aprovado set. 2016 